\title{
The Mid-Term Model Forecast Test of North China Rainstorm from July 19th to 20th, 2016
}

\author{
Xiakun Zhang1, Qiqi Liu², Manyu Zhang \\ ${ }^{1}$ National Meteorological Center of CMA, Beijing, China \\ ${ }^{2}$ College of Atmospheric Sciences, Nanjing University of Information Science \& Technology, Nanjing, China \\ ${ }^{3}$ School of Geography and Remote Sensing, Nanjing University of Information Science \& Technology, Nanjing, China \\ Email:zhangxk@cma.gov.cn
}

How to cite this paper: Zhang, X.K., Liu, Q.Q. and Zhang, M.Y. (2017) The MidTerm Model Forecast Test of North China Rainstorm from July 19th to 20th, 2016. Journal of Geoscience and Environment Protection, 5, 166-180.

https://doi.org/10.4236/gep.2017.58014

Received: July 7, 2017

Accepted: August 1, 2017

Published: August 4, 2017

Copyright $\odot 2017$ by authors and Scientific Research Publishing Inc. This work is licensed under the Creative Commons Attribution International License (CC BY 4.0).

http://creativecommons.org/licenses/by/4.0/

\begin{abstract}
Heavy rain is a kind of severe weather, often causing floods and serious soil erosion, leading to engineering losses, embankment rupture and crop flooding and other significant economic losses. Especially for some low-lying terrain areas, rainwater cannot quickly vent caused by farm water and soil moisture being too saturated, so it will cause more geological disasters. This article combines live and forecast data, aiming at the results of the mid-rainstorm forecast in North China during the period of 7.19-2016, and compares with the actual situation of rainstorm. We carry out the mid-term forecast of the rainstorm. The atmosphere is a kind of medium with various fluctuation phenomena, and its physical properties and changes are studied by the analysis of volatility which is an important research method. It is important to improve the accuracy of such severe weather forecasting rainstorms and to take precautionary measures in a timely manner to minimize the losses caused by rainstorms.
\end{abstract}

\section{Keywords}

Heavy Rain, North China, Medium-Term Model, Forecast Test

\section{Introduction}

During July 19 to 20,2016, the rainfall processed in most areas of the North China, mostly in Hebei Province, which caused floods in some parts of the province. And this caused multiple landslides and debris flow disasters. This has led some people to be besieged, and the death and disappearance of personnel.

According to incomplete statistics, as of 08:00 08, the province's 11 prefectures and Dingzhou City, Xinji City, a total of 142.86 million people affected by the disaster. 35 people died due to disaster, missing 77 people, collapsed housing 27,890 , damaged housing 83,108 , crop affected area of 536 thousand hectares, 
harvest area of 17 thousand hectares. The direct economic losses caused by the disaster have reached 8.642 billion yuan. Up to now, all over the emergency resettlement resettled 211,642 people.

Therefore, it is of great significance to strengthen the study of medium-term forecasting of catastrophic weather events such as heavy rain, to prevent the devastating weather, to reduce the damage caused by the disaster and to protect the life and property of the masses.

Numerical weather prediction is based on the actual situation of the atmosphere, at a certain initial value and boundary conditions, through a large computer for numerical calculation, describing the evolution of the process of hydrodynamics and thermodynamic equations [1] [2], to predict the future Time of atmospheric movement and weather phenomena. The numerical weather forecast is different from the classic weather forecast. It is a quantitative and objective forecast. Because of this, the numerical weather forecast first requires the establishment of a better (short-term, medium-term) numerical forecasting model that reflects the forecast period and the calculation method with less error, stable calculation and relatively faster operation. According to the actual situation of the atmosphere, the hydrodynamics and thermodynamic equations describing the evolution of the weather are solved by numerical calculation under certain initial and boundary conditions. And generally, using weather methods, combined with experience to produce the weather forecast is different. This forecast is a quantitative and objective forecast. More than 30 countries and regions around the world have used numerical weather forecasts as the main method of making daily weather forecasts. For the forecast project, it contains air pressure, temperature, humidity, wind, cloud and precipitation [3] [4] [5] [6]. In terms of the range, it has developed from the troposphere limited to the hemisphere including the stratosphere and the global scope.

However, since the atmosphere is a continuous medium with a continuous motion scale spectrum, there is always some movement that is close to or less than the scale of the grid, regardless of the resolution of the pattern (see the commonly used numerical method for numerical weather forecasting) [7]. The model is reflected exactly. Secondly, although the numerical solution of some stable equations of linear differential equations can be proved under appropriate conditions, the real solutions of the corresponding differential equations can be approximated, but for the nonlinear differential equations, the two solutions may not Exactly the same. The above problems are the problems encountered in the processing and analysis of numerical weather forecast data. These problems have not been solved yet [8] [9]. The root cause, or the understanding of the law of the evolution of the weather, especially on the medium and long-term weather process and the occurrence and development of strong storms, is not enough. This requires a combination of medium-term forecasts to improve the accuracy of weather detection and forecast accuracy. The mid-term weather forecast is a forecast for weather trends over the next four to ten days. General release of precipitation, temperature and precipitation forecast, therefore, to strengthen the 
storm of such a severe weather phenomenon of medium-term forecast study, can more accurately predict heavy rain and other severe weather [10]. After entering the 1970s, due to the development of production and the needs of economic activities, numerical weather forecast has been from short extended to medium term. The European Medium Weather Forecast Center designs the model for the physical process characteristics of medium-term weather, using it for time integration up to 10 days. The United States has made short-term forecast in the more sophisticated model, and then its forecast value as the initial value of the relatively simple input model for 3 to 8 days of extended forecast. They have achieved some success. Especially the European Center's forecast is more recognized.

\section{Materials and Methods}

The live data used in this study were obtained from the Central Meteorological Observatory and the forecast data were obtained from the ECMWF (European Center for Medium-Range Weather Forecast [11] [12]).

The atmosphere is a kind of medium with various fluctuation phenomena, using the analysis of volatility to study its physical properties and changes in the law is an important research method. The flow of daily atmospheric movement type and meteorological elements of the change is always showing some fluctuations features that it shows are different scales of disturbance to the weather common influence. In order to gain insight into the various scales of interference moving in the circulation of the atmosphere and some of the weather use, to enhance our understanding of the physical mechanism of the weather process, often need to carry out spectral decomposition, the atmospheric movement in the scale into divide the different waves. In order to examine the rows of a single wave, we compare their role in circulation adjustment and the weather. The process of the contribution to expose its evolution and its weather. There is a physical connection.

\section{Results and Analysis}

\subsection{Comparison of EC Monthly Forecast and Actuality of Precipitation in Jianghan, Huanghuai and North China from July 18 to 20}

EC precipitation monthly forecast reported at July 14 can see the northeastsouthwest to the rain belt situation. For Jianghan, Huanghuai area rain belt, we give a better forecast, but the rainfall is too small.

Due to the complex climate in the context of El Niño, the Yellow River cyclone developed northward abnormally. EC model has a large deviation in forecasting cyclone development, and the precipitation intensity forecast in north China is weak and the extreme degree of precipitation is poor.

The forecast from July 18 gave a strong forecast of the rain belt in North China, but the precipitation intensity forecast is still weaker than the actual situation. At the same time, Jianghan region forecast rainfall is also weak. The results are shown in Figure 1. 


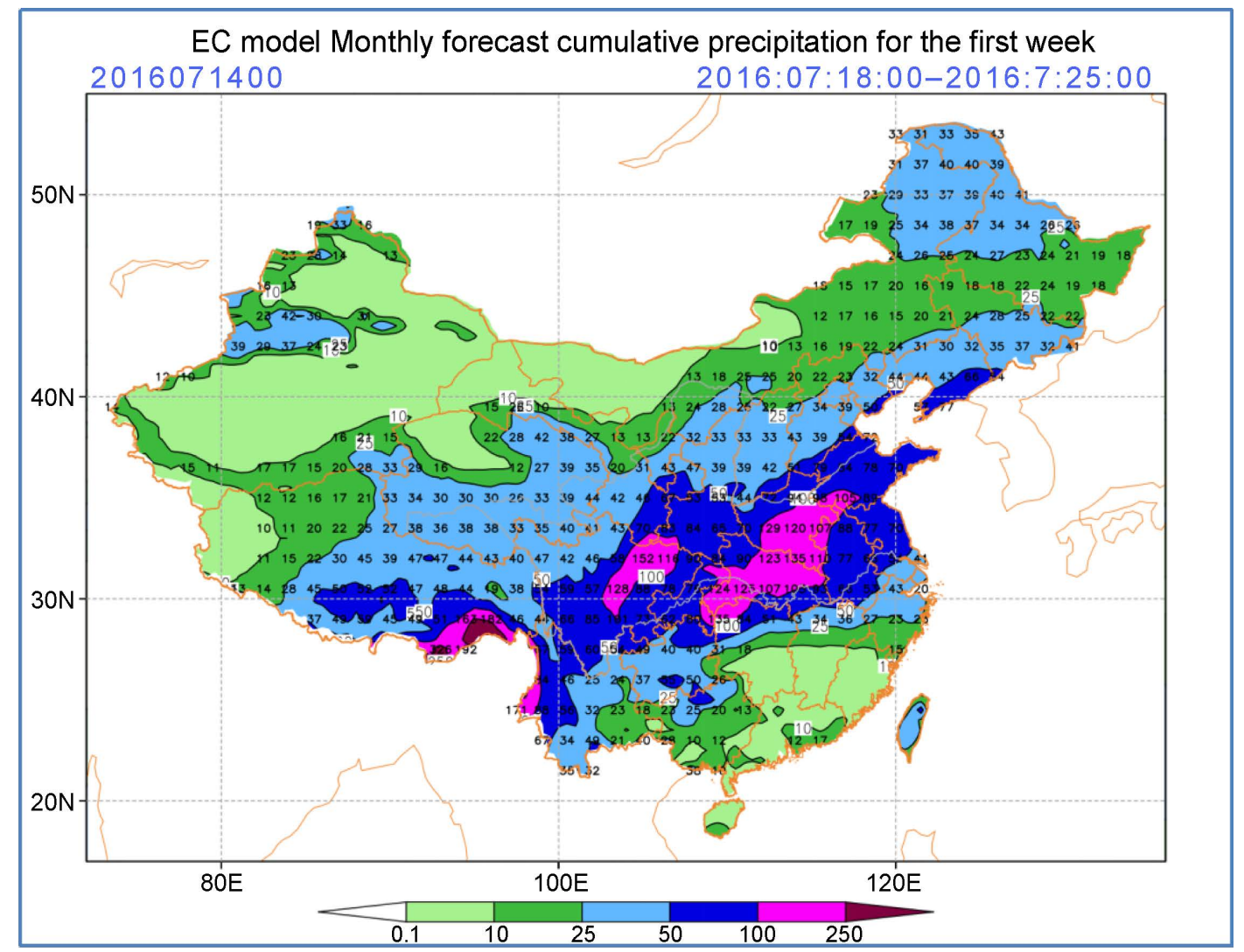

(a)

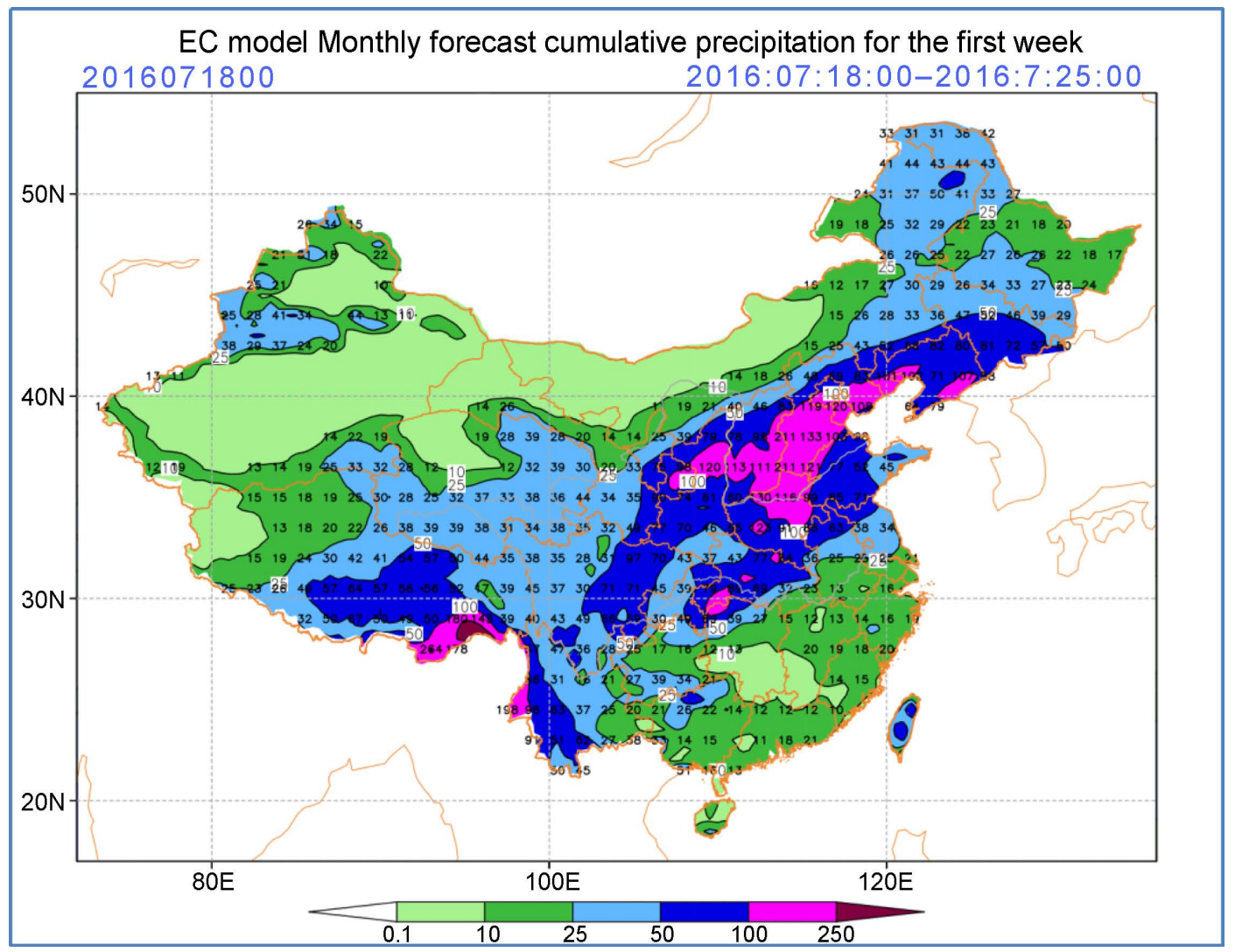

(b) 


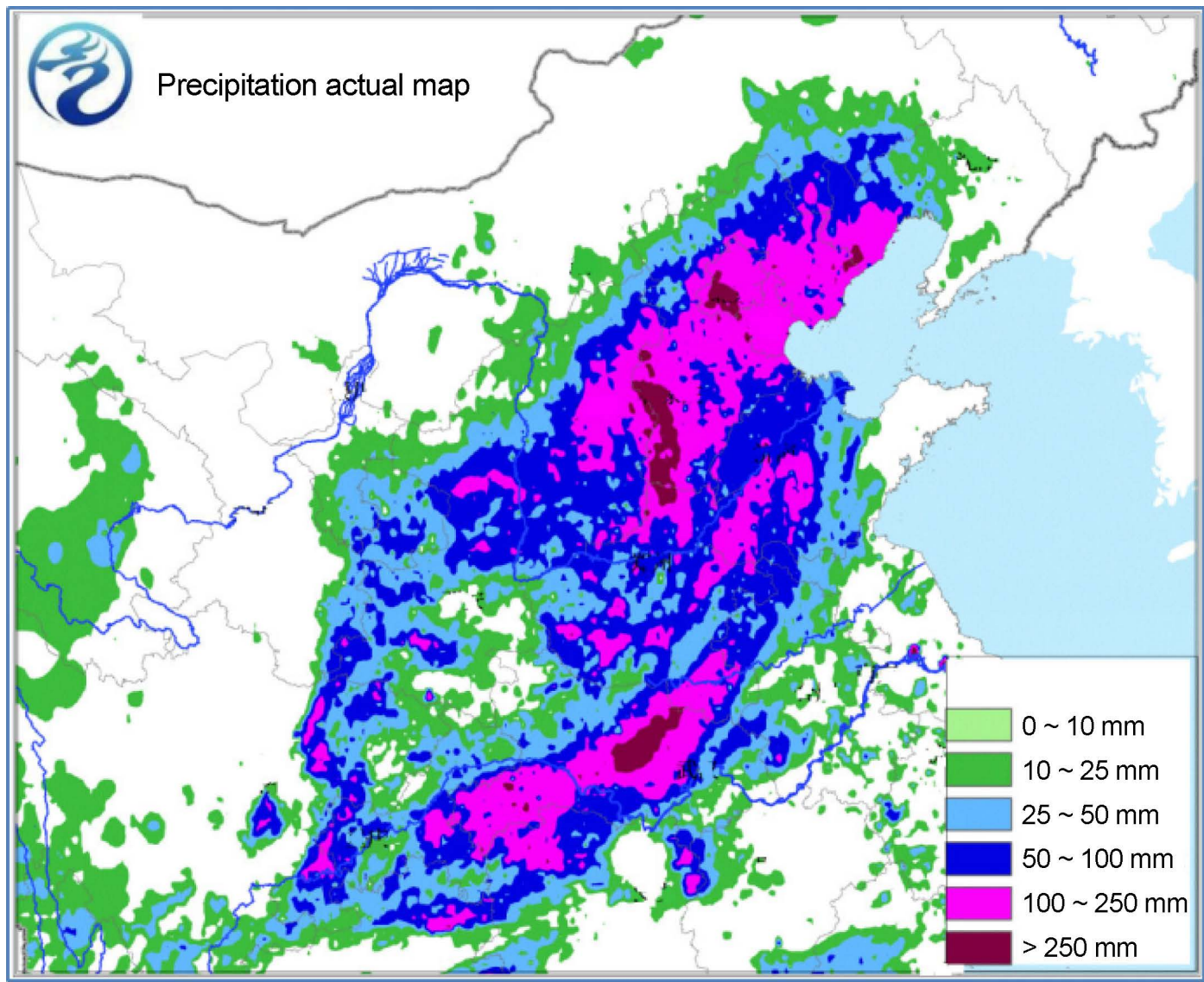

(c)

Figure 1. Comparison of EC monthly forecast and actuality of precipitation in Jianghan, Huanghuai and North China from July 18 to 20. (a) EC model monthly forecast cumulative precipitation for the first week; (b) EC model monthly forecast cumulative precipitation for the first week; (c) Precipitation actual map.

EC month forecast 3 to 4 weeks before the forecast for this precipitation are without any forecasting skills. 2 weeks ago forecast heavy rainfall belt is located in the Yangtze River, than the live south.

The forecast of "+" "-" "+" type prediction jumps in the forecast of precipitation in North China from different reporting times. See Figure 2.

\subsection{Jianghan, Huanghuai and North China EC Extreme Precipitation Monthly Forecast from July 18 to20 (33\% Probability)}

EC Monthly forecast 3 to 4 weeks before the forecast for $10 \%$ extreme precipitation without any indication. 2 weeks ago (July 11 reported that) extreme precipitation occurred in Jianghan, Huanghuai area. July 14 forecast precipitation in North China is lower than normal, to July 18 forecast to give extreme precipitation in North China. See Figure 3 for details. Avoid combining SI and CGS units, such as current in amperes and magnetic field in oersteds. This often leads to confusion because equations do not balance dimensionally. If you must use mixed units, clearly state the units for each quantity that you use in an equation. 


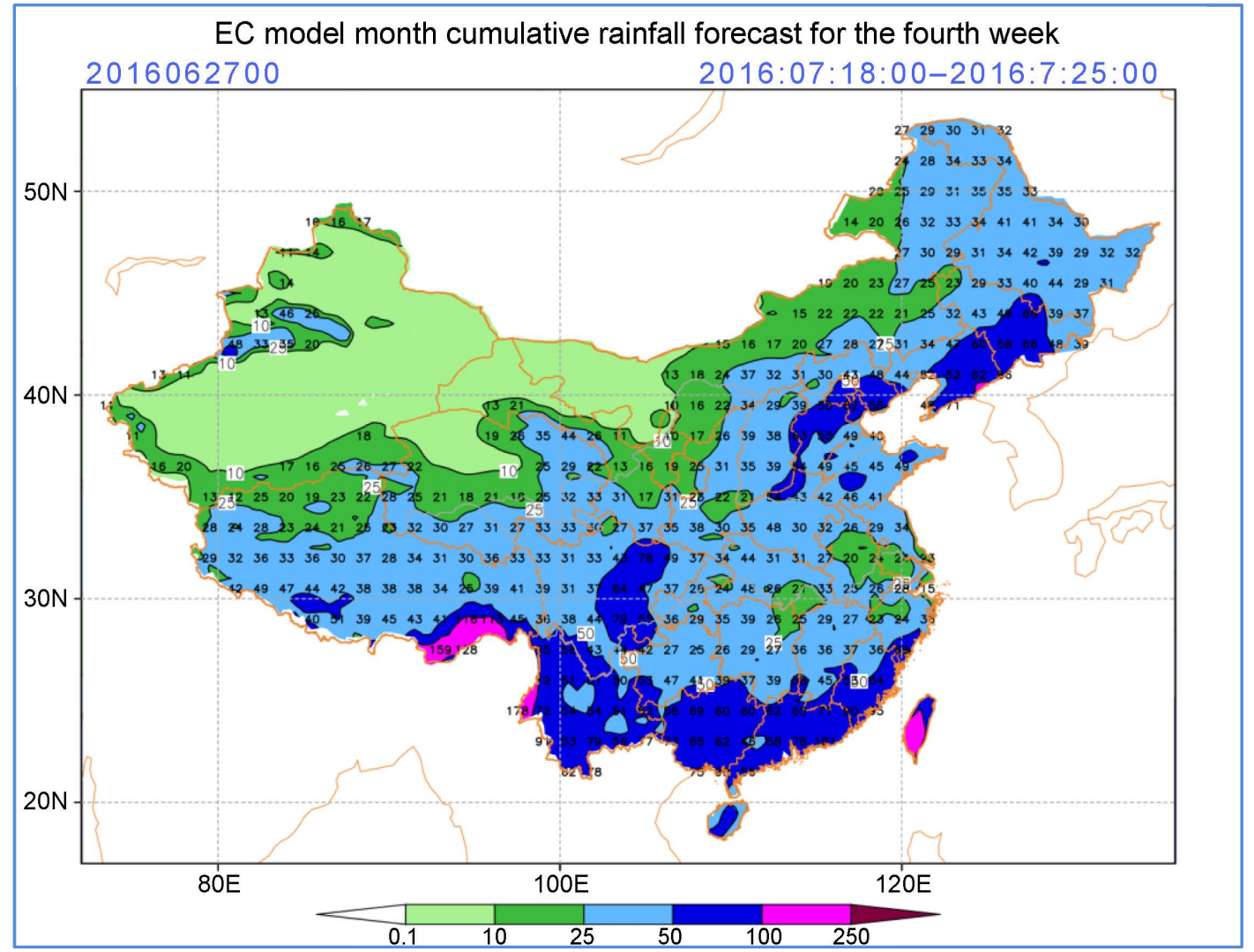

(a)

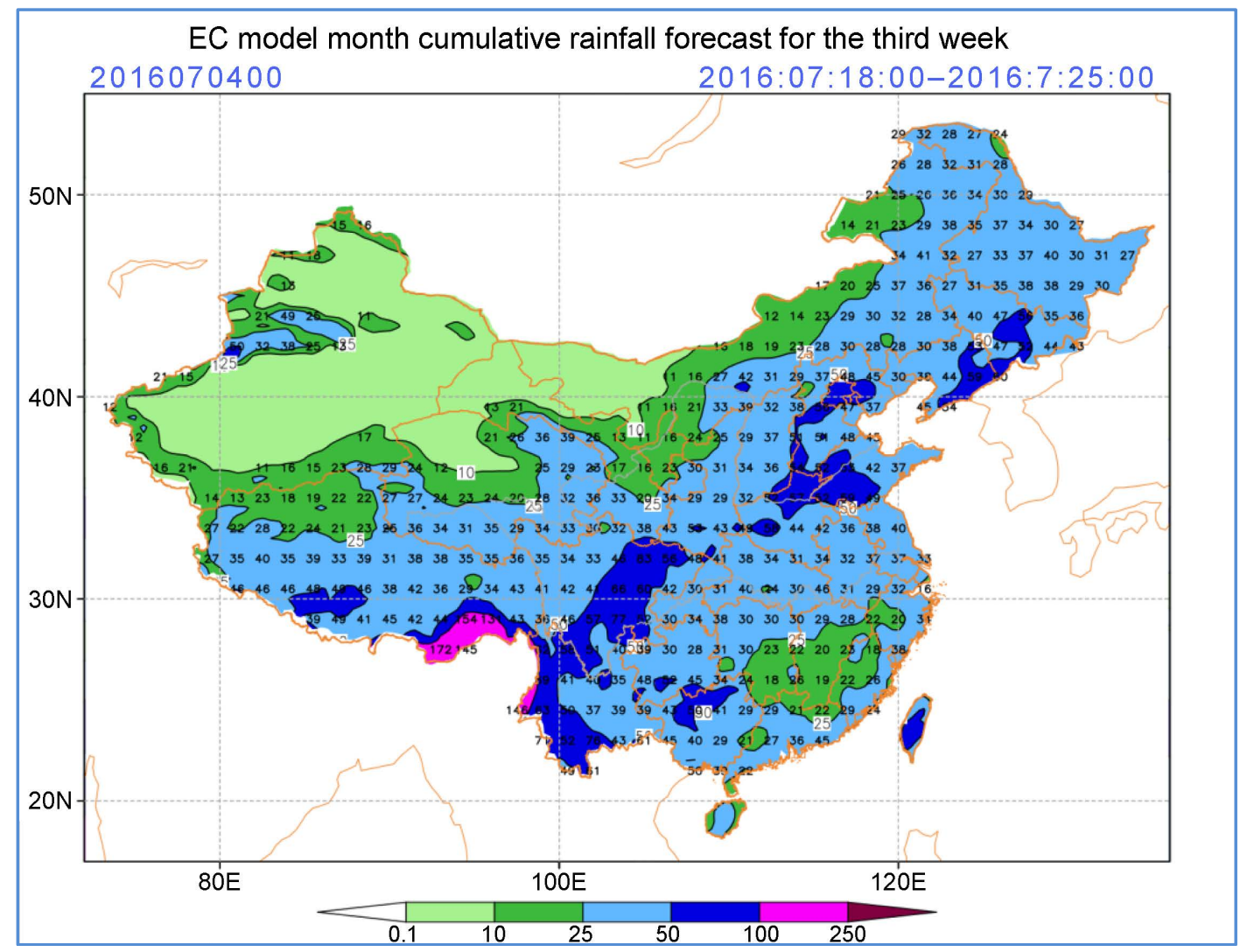

(b) 


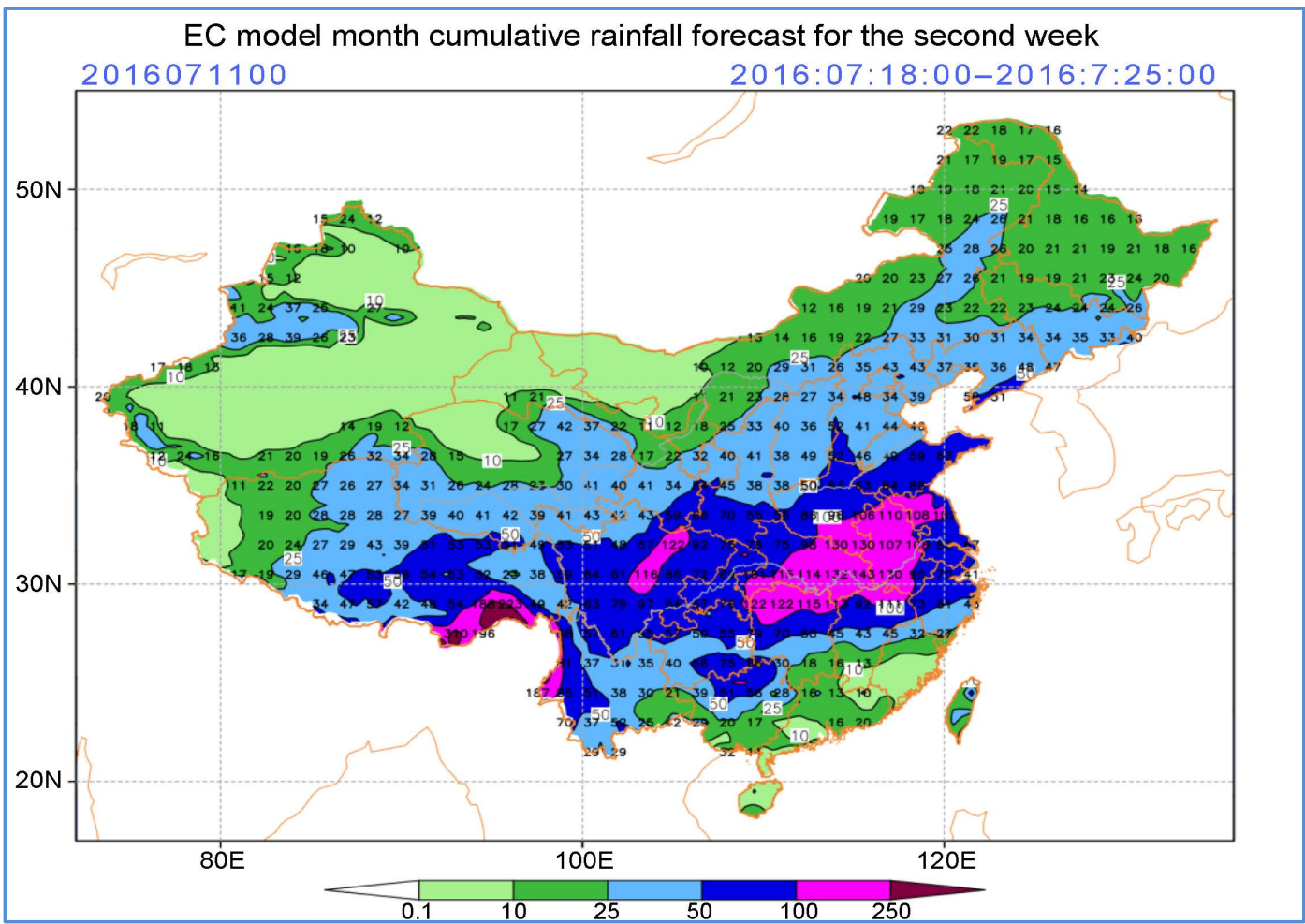

(c)

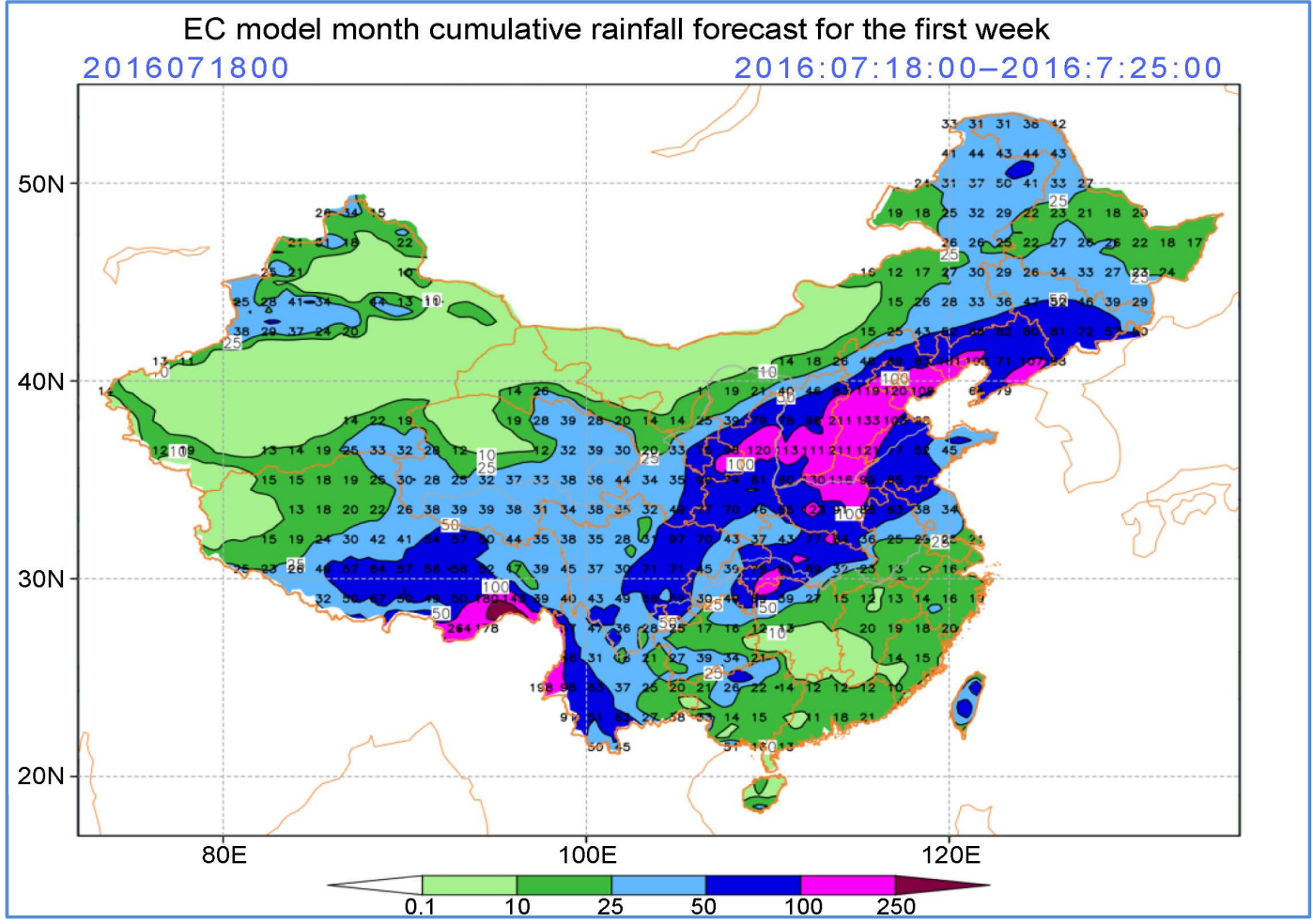

(d)

Figure 2. EC model monthly forecast week cumulative precipitation. (a) EC model month cumulative rainfall forecast for the fourth week; (b) EC model month cumulative rainfall forecast for the third week; (c) EC model month cumulative rainfall forecast for the second week; (d) EC model month cumulative rainfall forecast for the first week. 


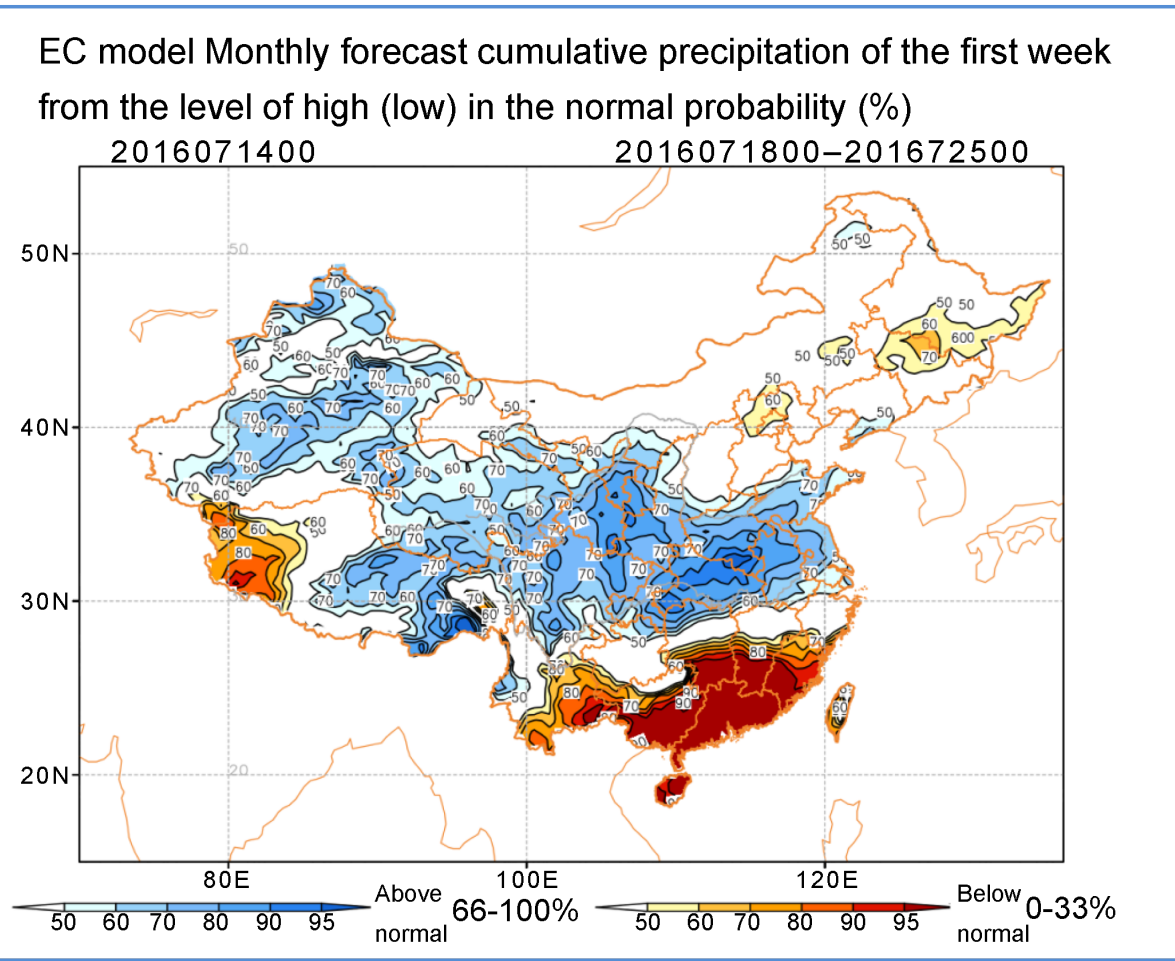

(a)

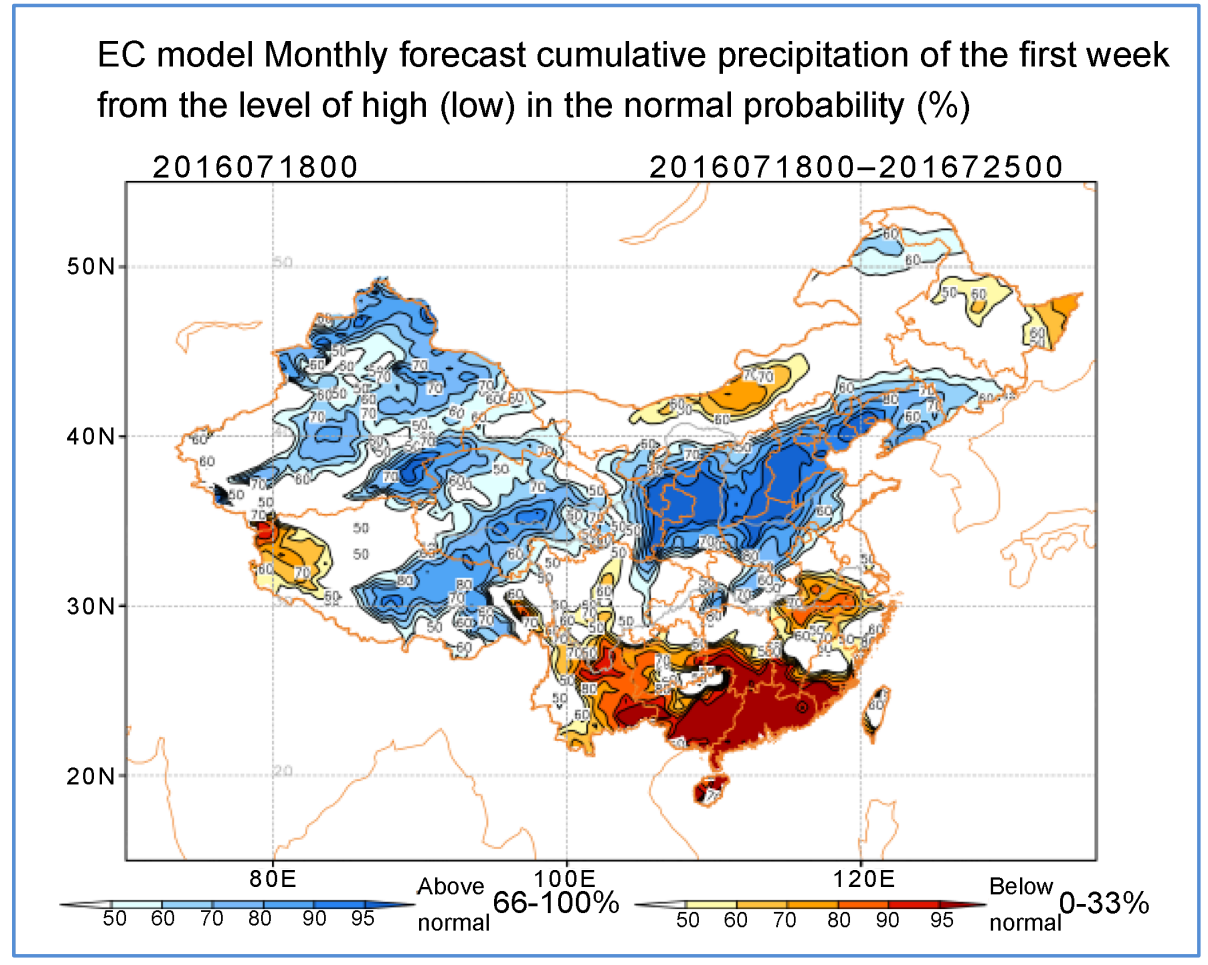

(b)

Figure 3. The forecast of EC extreme precipitation month in Jianghan, Huanghuai and North China from July 18 to 20. (a) EC model monthly forecast cumulative precipitation of the first week from the level of high (low) in the normal probability (\%); (b) EC model monthly forecast cumulative precipitation of the first week from the level of high (low) in the normal probability (\%). 


\subsection{Jianghan, Huanghuai and North China EC Extreme Precipitation Monthly Forecast from July 18 to20 (10\% Probability)}

EC Monthly forecast 3 to 4 weeks before the forecast for $10 \%$ extreme precipitation are without any indication. 2 weeks ago (July 11 reported that) extreme precipitation occurred in Jianghan, Huanghuai area. The forecast for July 14 has reduced the probability and area of heavy precipitation. To the July 18 forecast to give extreme precipitation in North China. See Figure 4 for details.

\subsection{Comparison of EC 850 hPa Wind Field Monthly Forecast and Live}

EC month forecast 3 to 4 weeks before the forecast think that the eastern part of China's $850 \mathrm{hPa}$ for the southwest airflow. 2 weeks ago in Jianghan, Huanghuai area forecast a shear line. To the July 18 forecast in the northern part of North China to see a low vortex appears.

This should also be a reason of EC month forecast 2 - 4 weeks forecast rain belt position, rainfall deviation. Contrast is shown in Figure 5 .

\subsection{Comparison of Monthly Forecast and Live Condition of EC $500 \mathrm{hPa}$ Wind Field}

The $500 \mathrm{hPa}$ subtropical high ridge line is located at $24^{\circ} \mathrm{N}$. 588 line west to $108^{\circ} \mathrm{E}$. In the high latitude degree, there is a high-altitude tank near the Lake Baikal.

EC month forecast 3 to 4 weeks before the forecast that the subtropical high ridge line at $30^{\circ} \mathrm{N}$, which is north than the real situation. In the high latitude is the zonal airflow. To 1 to 2 weeks forecast to gradually close to the real situation. Contrast is shown in Figure 6.

\subsection{Comparison of Forecast and Live of EC 200 hPa Height Field Monthly}

Live $200 \mathrm{hPa}$ South Asia high-pressure ridge eastward extension to the eastern part of China's Huanghuai between.

The monthly forecast of the $200 \mathrm{hPa}$ South Asia high-pressure ridge is located between the Yangtze River Basin and the JAC. Contrast is shown in Figure 7.

\section{Conclusions}

In this paper, the mid-term forecast transition of heavy rainstorm in North China from 19 to 20 July 2016 was analyzed by using conventional meteorological observation data and EC set forecast data. We get the following main conclusions:

1) The EC collection forecast shows a significant change in the forecast of the position and intensity of the rain belt around July 16th. It started $5 \mathrm{~d}$ ahead of a better forecasting ability. The transition of the belt position and intensity is caused by the impact of the system forecast. EC set forecast from the beginning 


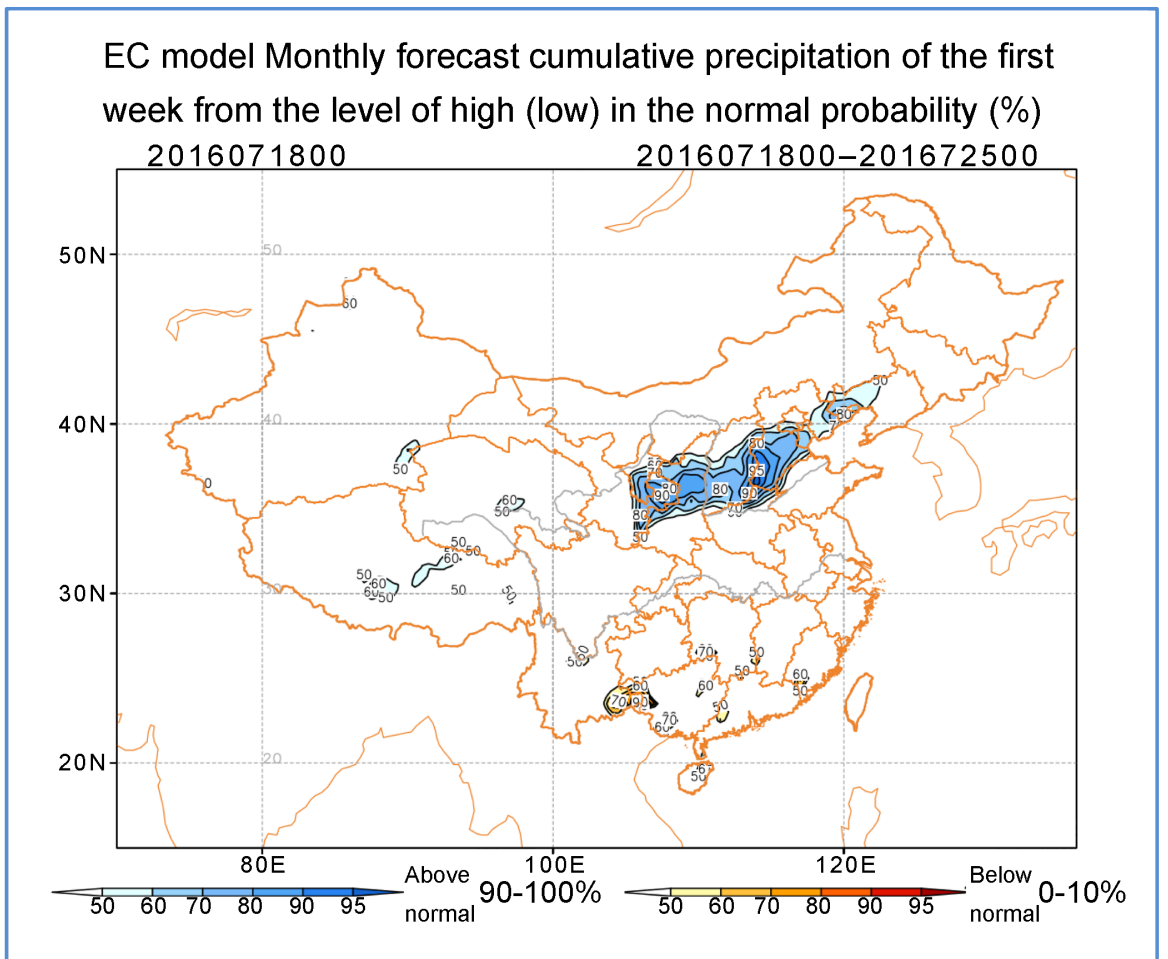

(a)

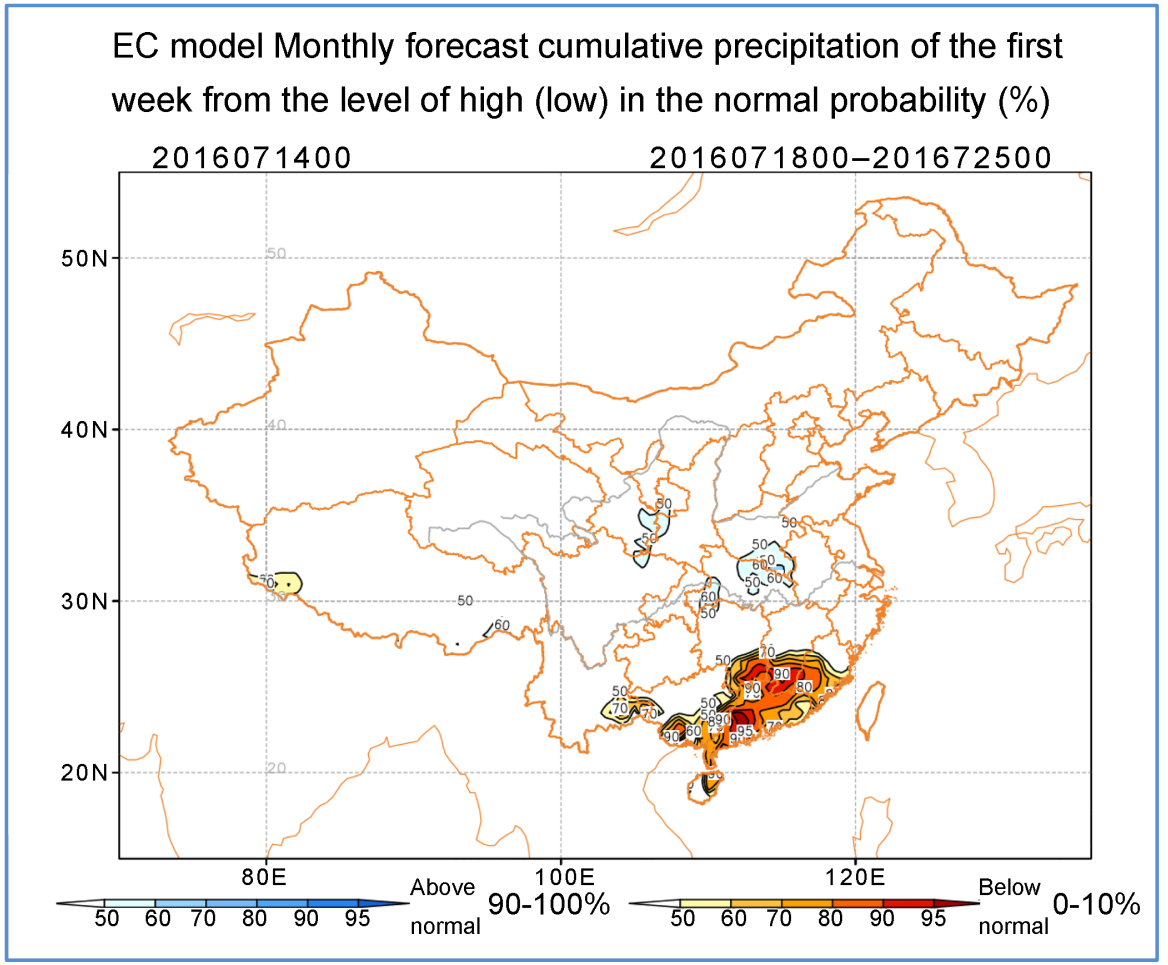

(b)

Figure 4. The forecast of EC extreme precipitation month in Jianghan, Huanghuai and North China from July 18 to 20. (a) EC model monthly forecast cumulative precipitation of the first week from the level of high (low) in the normal probability (\%); (b) EC model monthly forecast cumulative precipitation of the first week from the level of high (low) in the normal probability (\%). 


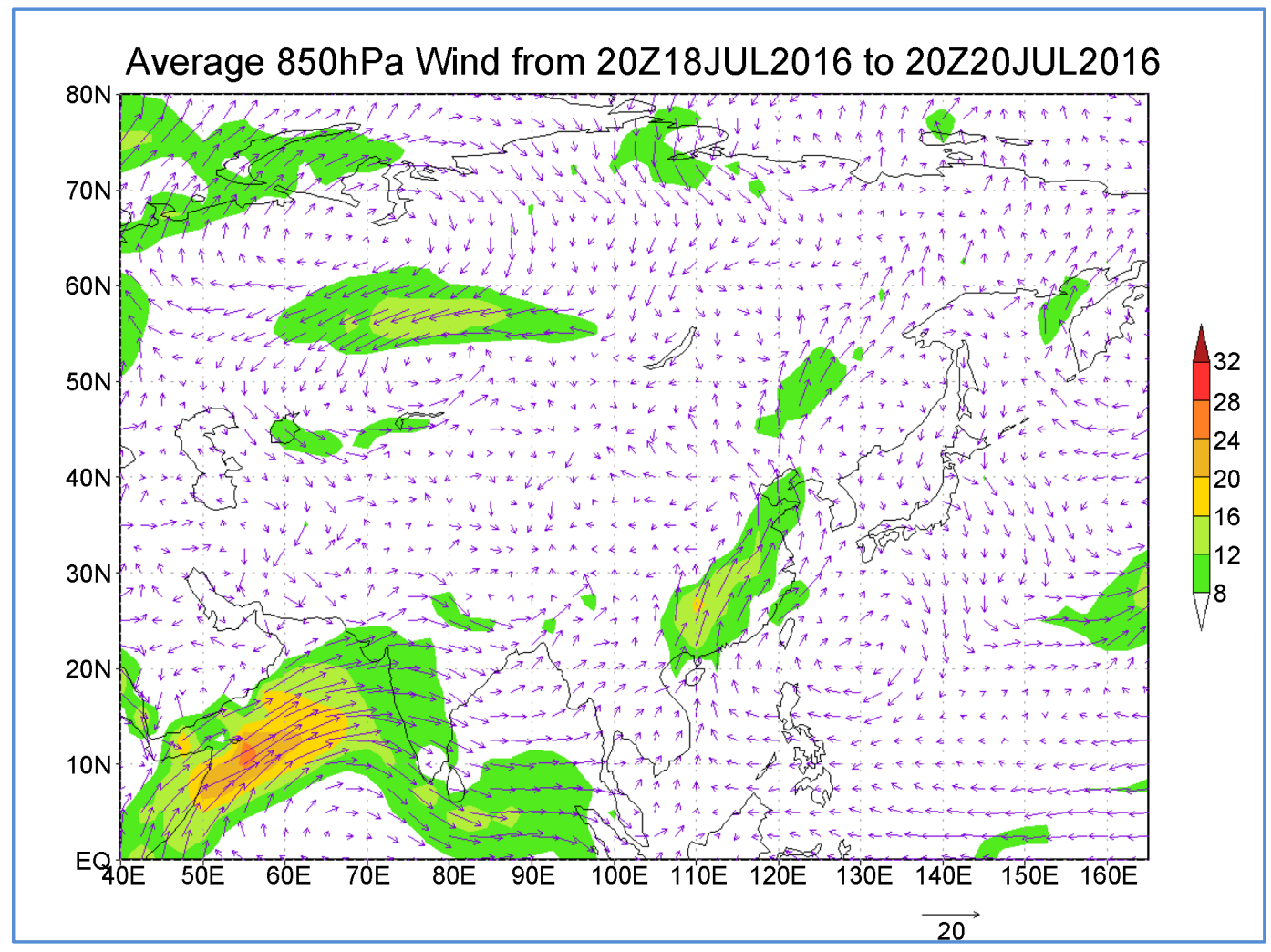

(a)

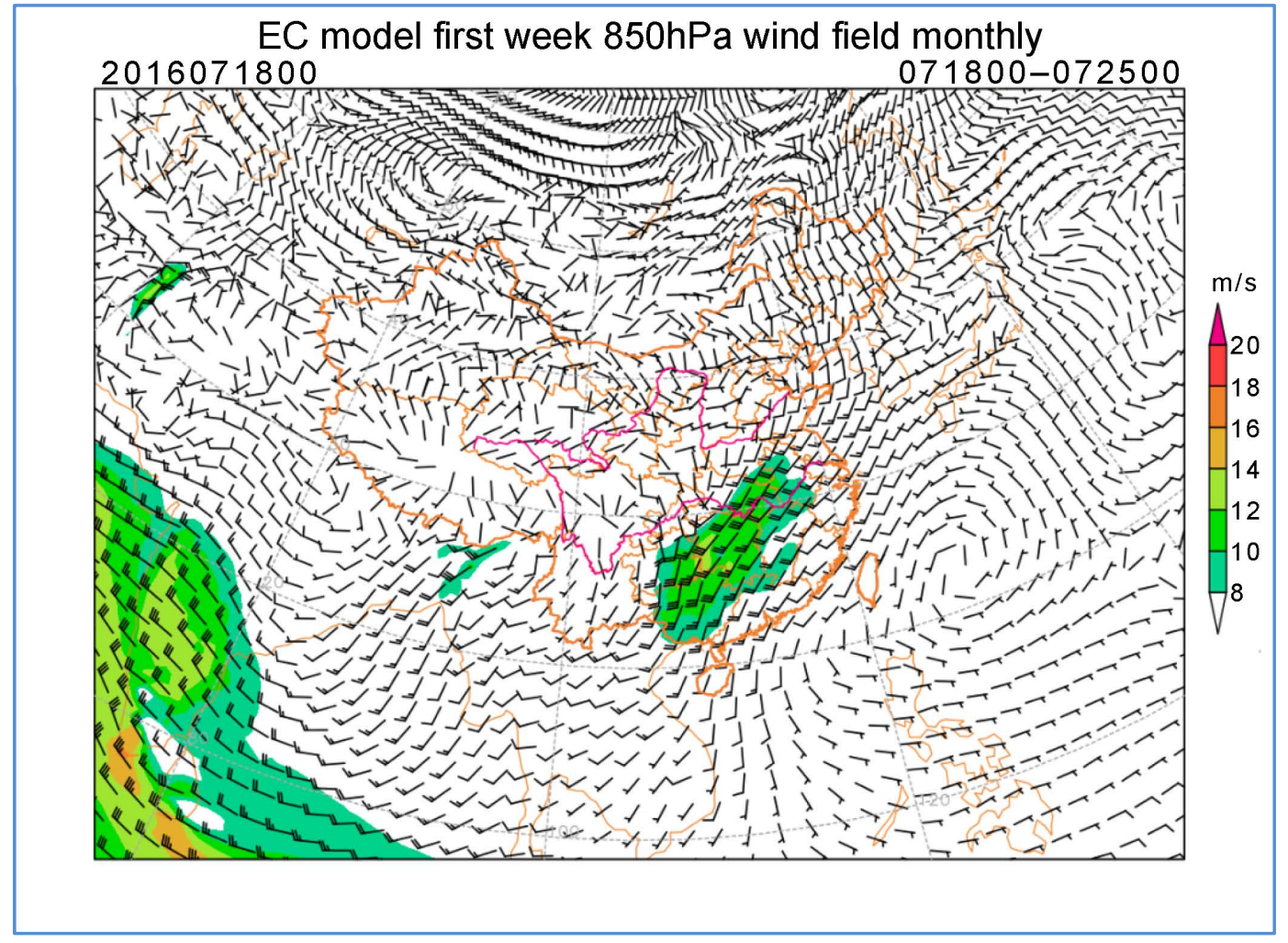

(b)

Figure 5. Comparison of EC $850 \mathrm{hPa}$ wind field monthly forecast and live. (a) $850 \mathrm{hPa}$ live wind field; (b) EC model first week $850 \mathrm{hPa}$ wind field monthly forecast. 


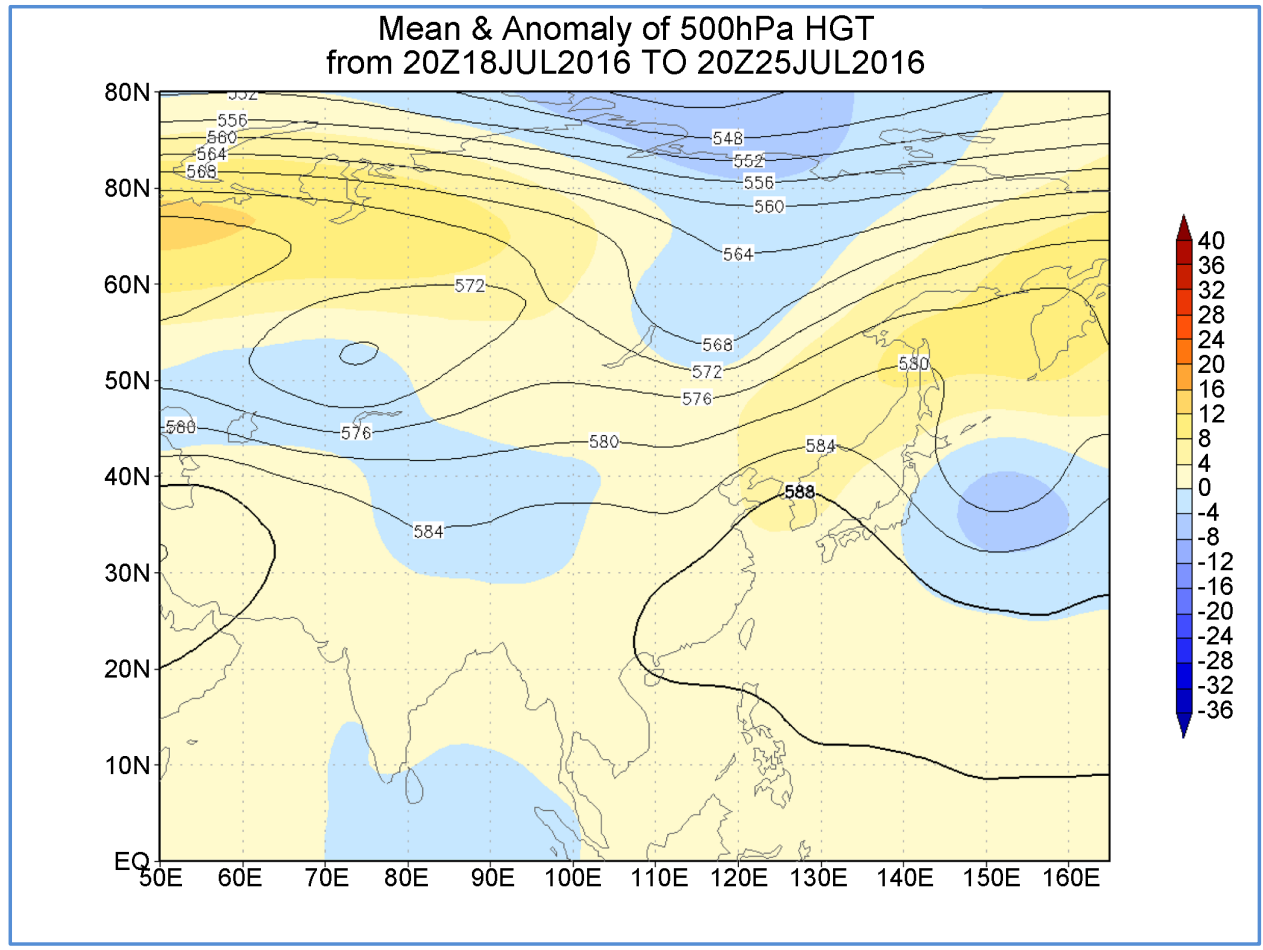

(a)

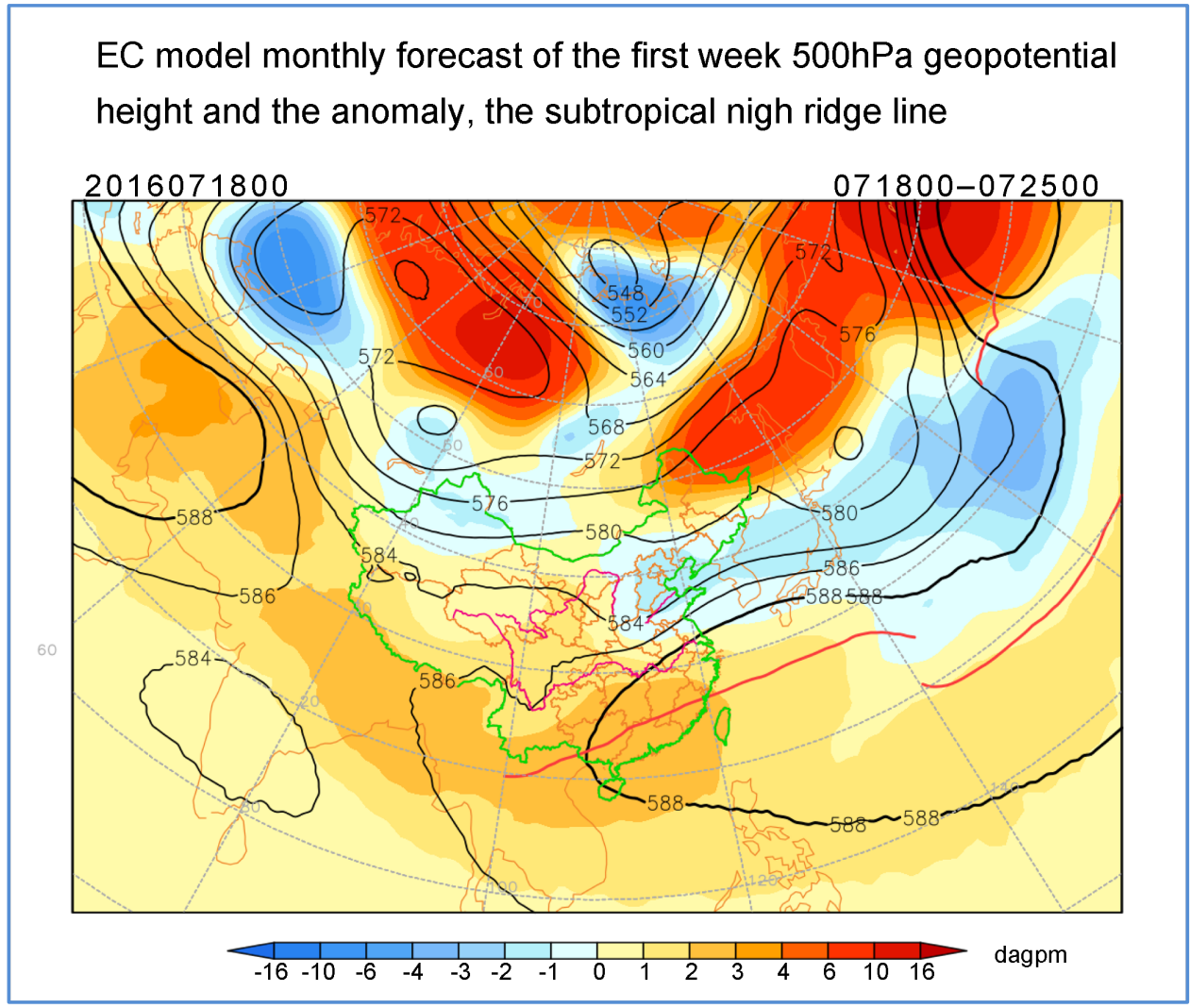

(b)

Figure 6. Comparison of EC $500 \mathrm{hPa}$ wind field monthly forecast and live. (a) $500 \mathrm{hPa}$ live wind field; (b) EC model monthly forecast of the first week $500 \mathrm{hPa}$ geopotential height and the anomaly, the subtropical high ridge line. 


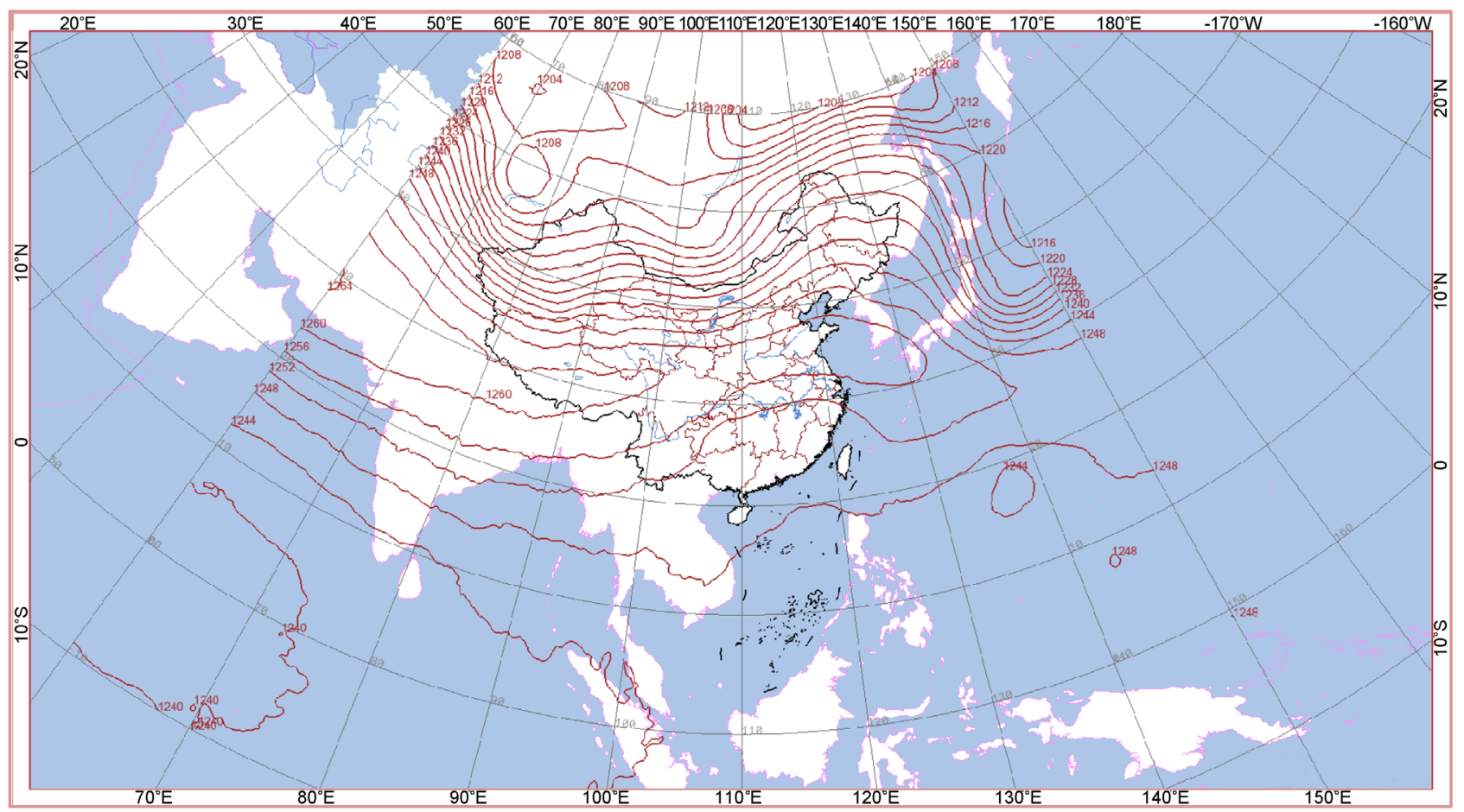

(a)

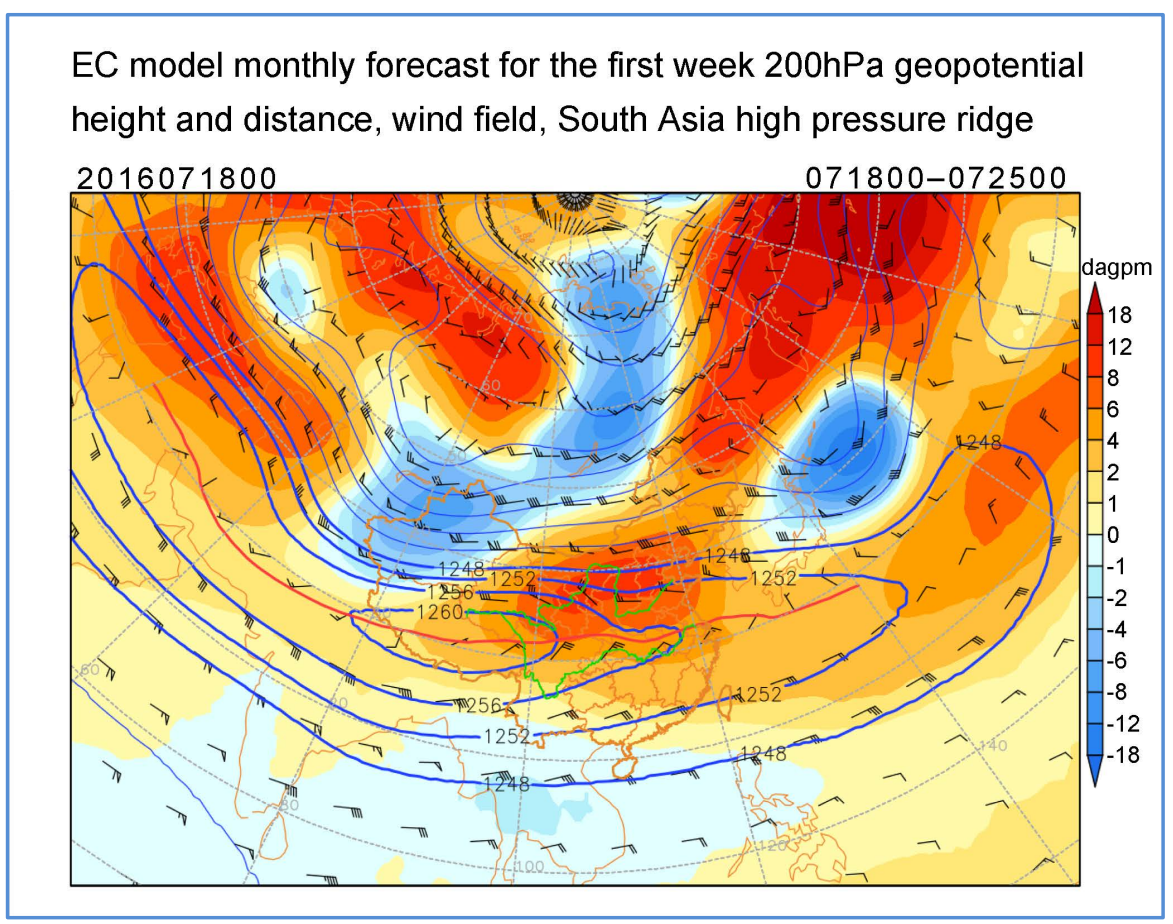

(b)

Figure 7. Comparison of EC $200 \mathrm{hPa}$ wind field monthly forecast and live. (a) $200 \mathrm{hPa}$ height field and live; (b) EC model monthly forecast for the first week $200 \mathrm{hPa}$ geopotential height and distance, wind field, South Asia high pressure ridge.

of the newspaper reported on the 15th reported, near the $500 \mathrm{hPa}$ low trough by the downstream to strengthen the high pressure ridge block, slowly eastward development. So it formed an "East high west low" stability situation. While the 
lower-level southwest vortex and southwest jet forecast position is northerly stronger intensity.

2) The height difference of the $500 \mathrm{hPa}$ latitude potential of the ensemble forecast is obvious from $8 \mathrm{~d}$ in advance. "East high west low" type relative rainfall forecast has better predictability. The change trend can provide reference for the medium-term forecast of heavy rainfall in North China.

Medium-term forecast in Europe and the United States have achieved some success. Especially the European Center's forecast is more recognized. But because of the weather process and weather phenomena affected by many factors, with a certain degree of randomness, it is soon found that with the extension of forecasting time, the accuracy of the forecast is declining rapidly, which makes the mid-term weather forecast very difficult. Therefore, to improve the accuracy of the medium-term forecast is still an important part of future research.

\section{Acknowledgements}

This work was supported by the National Meteorological Center Youth Fund (Q201603 and Q201703), China.

\section{References}

[1] Bauer, P., Thorpe, A. and Brunet, G. (2015) The Quiet Revolution of Numerical Weather Prediction. Nature, 525, 47-55. https://doi.org/10.1038/nature14956

[2] Chen, N., Qian, Z., Nabney, I.T., et al. (2014) Wind Power Forecasts Using Gaussian Processes and Numerical Weather Prediction. IEEE Transactions on Power Systems, 29, 656-665. https://doi.org/10.1109/TPWRS.2013.2282366

[3] Perez, R., Lorenz, E., Pelland, S., et al. (2013) Comparison of Numerical Weather Prediction Solar Irradiance Forecasts in the US, Canada and Europe. Solar Energy, 94, 305-326. https://doi.org/10.1016/j.solener.2013.05.005

[4] Palmer, T. (2017) The Primacy of Doubt: Evolution of Numerical Weather Prediction from Determinism to Probability. Journal of Advances in Modeling Earth Systems, 9, 730-734. https://doi.org/10.1002/2017MS000999

[5] Couvreux, F., Bazile, E., Canut, G., et al. (2016) Boundary-Layer Turbulent Processes and Mesoscale Variability Represented by Numerical Weather Prediction Models during the BLLAST Campaign. Atmospheric Chemistry and Physics, 16, 8983-9002. https://doi.org/10.5194/acp-16-8983-2016

[6] Shuman, F.G. (1978) Numerical Weather Prediction. Bulletin of the American Meteorological Society, 59, 5-17. https://doi.org/10.1175/1520-0477(1978)059<0005:NWP>2.0.CO;2

[7] Perez, R., Kivalov, S., Schlemmer, J., et al. (2010) Validation of Short and Medium Term Operational Solar Radiation Forecasts in the US. Solar Energy, 84, 2161-2172. https://doi.org/10.1016/j.solener.2010.08.014

[8] Yalcinoz, T. and Eminoglu, U. (2005) Short Term and Medium Term Power Distribution Load Forecasting by Neural Networks. Energy Conversion and Management, 46, 1393-1405. https://doi.org/10.1016/j.enconman.2004.07.005

[9] De Felice, M., Alessandri, A. and Catalano, F. (2015) Seasonal Climate Forecasts for Medium-Term Electricity Demand Forecasting. Applied Energy, 137, 435-444. https://doi.org/10.1016/j.apenergy.2014.10.030 
[10] Bello, A., Reneses, J., Muñoz, A., et al. (2016) Probabilistic Forecasting of Hourly Electricity Prices in the Medium-Term Using Spatial Interpolation Techniques. International Journal of Forecasting, 32, 966-980. https://doi.org/10.1016/j.ijforecast.2015.06.002

[11] Matsueda, M. and Palmer, T. (2017) Predictability of Winter Pacific Weather Regimes and Its Connections with MJO on Medium-Range Timescales. 19th EGU General Assembly, EGU2017, Proceedings from the Conference, Vienna, 23-28 April 2017, 9149.

[12] Davis, C.A., Ahijevych, D.A., Wang, W., et al. (2016) Evaluating Medium-Range Tropical Cyclone Forecasts in Uniform-and Variable-Resolution Global Models. Monthly Weather Review, 144, 4141-4160.

https://doi.org/10.1175/MWR-D-16-0021.1

Submit or recommend next manuscript to SCIRP and we will provide best service for you:

Accepting pre-submission inquiries through Email, Facebook, LinkedIn, Twitter, etc. A wide selection of journals (inclusive of 9 subjects, more than 200 journals)

Providing 24-hour high-quality service

User-friendly online submission system

Fair and swift peer-review system

Efficient typesetting and proofreading procedure

Display of the result of downloads and visits, as well as the number of cited articles

Maximum dissemination of your research work

Submit your manuscript at: http://papersubmission.scirp.org/

Or contact gep@scirp.org 